Volume 10 Issue 1 (2021) Pages 43-52

Ta'dib: Jurnal Pendidikan Islam

ISSN: 2528-5092 (Online) 1411-8173 (Print)

https://ejournal.unisba.ac.id/index.php/tadib/article/view/7557

\title{
THE RESPONSIBILITIES OF ISLAMIC RELIGIOUS EDUCATION TEACHERS IN IMPLANTING ISLAMIC VALUES FOR STUDENTS
}

\author{
Misranik \\ Program Studi Manajemen Pendidikan Islam, Pascasarjana UIN STS Jambi \\ Email:misranik6@gmail.com \\ DOI: https://doi.org/10.29313/tjpi.v10i1.7557 \\ Received: January 29th, 2020. Accepted: May 1th, 2021. Published: May 1th, 2021.
}

\begin{abstract}
This study aims to determine the Islamic and the responsibility of Islamic religious education teachers in instilling Islamic values in students. This research uses a descriptive qualitative approach. In obtaining data researchers used interview, observation, and documentation methods. The results of this study concluded that: 1) The forms of Islamic values that are applied, the value of faith, the value of worship, and the value of morals. 2) Supporting factors for Islamic Religious Education teachers in instilling Islamic values in students, namely, the existence of a community in a very religious school environment, besides that it has full support from the principal and school committee, an appropriate school vision and mission, and existence Mentoring. 3) PAI teachers have carried out their duties and obligations as well as their responsibilities as PAI teachers to instill Islamic values in students, and all comply with the existing curriculum in schools, and Islamic religious education teachers in instilling Islamic values in students with babituation. 4) The results of Islamic activities, it can be seen that all students wear a headscarf for those who are Muslim, their behavior and behavior are also good, as well as many Islamic achievements achieved.
\end{abstract}

Keywords: Responsible, Implanting, Islamic V alues.

\begin{abstract}
Abstrak
Penelitian ini memiliki tujuan mengetahui keislaman dan tanggung jawab dari guru pendidikan Agama Islam dalam memberikan penanaman nilai-nilai keislaman pada siswa. Penelitian ini memanfaatkan pendekatan kualitatif deskriptif yang dalam mendapatkan datanya dengan metode wawancara, observasi, dan dokumentasi. Hasil penelitian ini mengungkapkan: 1) bentuk-bentuk niali keislaman yang diterapkan ialah, nilai iman, nilai ibadah, dan nilai akblak. 2) Faktor pendukung guru Pendidikan Agama Islam dalam menanamkan nilai-nilai keislaman pada siswa yaitu, adanya masyarakat di lingkungan sekolah yang sangat religius, selain itu mendapat dukungan penuh dari kepala sekolah dan komite sekolah, Visi Misi sekolah yang sesuai, dan adanya Mentoring. 3) guru PAI telah menjalankan tugas dan kewajibannya serta tanggung jawabnya sebagai guru PAI untuk menanamkan nilai-nilai keislman pada siswa, dan semua susuai dengan kurikulum yang ada di sekolah, dan guru pendidikan Agama Islam dalam menanamkan nilai-nilai keislaman pada siswa dengan pembiasaan. 4) Hasil kegiatan-kegiatan keislaman, terlihat bahwa siswi-siswi semua mengenakan jilbab bagi yang muslim, aklah serta tingkah laku siswa-siswinya juga baik, serta banyake prestasi-prestasi keislaman yang di raih.
\end{abstract}

Kata Kunci: Tanggung Jawab, Menanamkan, Nilai-nilai Keislaman 


\section{PENDAHULUAN}

Bidang Ilmu Pengetahuan dan Teknologi (IPTEK) terus berkembang cepat pada setiap komponen kehidupan manusia pada berbagai permasalahan hanya dapat diselesaikan kecuali dengan upaya penguasaan dan peningkatan di bidang IPTEK. Selain bermanfaat untuk kehidupan manusia, disisi lain juga dapat membawa perubahan yang akan membawa manusia ke dalam era persaingan global yang semakin ketat. Sebagai negara berkembang, bangsa ini perlu untuk terus untuk meninjau perkemangan dan peningkatan kualias sumber dana manusia agar dapat ikut serta dalam persaingan global. Oleh sebab itu, peningkatan kualitas sumber daya manusia adalah suatu kenyataan yang harus dilaksanakn dengan terencana, terarah, intensif, efektif dan efisien dalam proses pembangunan, kalau tidak ingin bangsa ini kalah bersaing dalam menjalani era globalisasi tersebut. (Sofan Amri, 2013: 285).

Pendidikan akan dapat membawa kemajuan individu dalam berbagai bidang bahkan akan mengangkat derajatnya di sisi Allah SWT. Hal tersebut sesuai dengan tujuan pendidikan yaitu, Allah Berfirman dalam surat Al-Mujadalah ayat 11:

“...Niscaya Allah meninggikan orangorang yang beriman di antara kamu dan orang-orang yang berilmu pengetahuan beberapa derajat...” (QS. Al-Mujadalah ayat 11).

Dari potongan ayat tersebut, terdapat kandungan bahwa Allah akan mengangkat derajat orang yang diberi ilmu beberapa derajat. Orang-orang yang dimaksud disini bisa merujuk pada seorang guru dan para siswa/peserta didik. Dari sini, ia mendapatkan tambahan ilmu, pemahaman, kemulian, dan prestasi. Guru mempunyai peran penting dalam suatu Pendidikan. Apabila diibaratkan, di pundah seorang guru terdapat beban besar yang harus dibawa salah satunya yaitu tanggungjawab besar atas kualitas Pendidikan. Oleh karena itu, guru dituntut untuk terus berkembang dalam hal ilmu pengetahuan dan berbagai keterampilan yang nantinya dibutuhkan untuk proses pembelajaran ataupun di luar pembelajaran.

Zakiyah Daradjat menjelaskan bahwa seorang guru didefinisikan sebagai pendidik profesionl dikarenakan guru memikul sebuah amanah dari orangtua untuk mendidik anakanaknya dengan baik. Menurut kesepakatan para ahli, Pendidikan akan berjalan lancar karena dijalankan oleh aspek dasar yaitu guru, siswa, kurikulum, serta sarana dan prasarana yang mendukung, faktor komponen manusia yang terlibat dalam pelaksanaan pendidikan adalah faktor yang paling menentukan. Peran guru yang berkualias sangat penting bagi suatu negara, terlebih lagi untuk suatu bangsa yang saat ini sedang gencar membangun perkembangan tekonologi yang semakin canggih dan mengalami perubahan serta pergeseran nilai yang cenderung memberikan kondisi pada kehidupan yang menuntut ilmu dan seni dalam kadar dinamik untuk dapat mengadaptasikan diri. (Mufron, 2013: 27-28) 
Saat ini, peran guru pendidikan agama Islam semakin dibutuhkan untuk menerapkan nilai-nilai agama islam seiring dengan perubahan sosial kehidupan masyarakat yang semakin menurun. Oleh karena itu, pendidikan agama islam sangat penting untuk masyarakat untuk perubahan yang lebih baik (Rohmat Mulyana, 2004:147).

Nilai-nilai agama islam yang melandasi suatu kematangan dalam beragama, menjadikan masyarakat dapat memperjelas dan menentukan sikap terhadap substansi nilai dan norma baru yang muncul dalam proses perubahan. Pendidikan dihadapkan dalam suatu permasalahan yang besar namun disisi lain Pendidikan juga dituntut dapat meningkatkan keterampilan dan membentuk karakter serta peradaban bangsa yang bermartabat agar siswa menjadi manusia yang beriman dan bertaqwa kepada Tuhan Yang Maha Esa (Mulyasa, 2011: 6).

Di suatu instansi pendidikan, penanaman nilai keagamaan adalah bentuk suatu bantuan untuk para siswa agar mengalami peningkatan dalam hal nilai religious serta dapat mengamalkannya secara moral dalam hidupnya. Hal tersebut dikarenakan hanya dengan cara ini peserta didik mampu menyadari akan petingnya nilai keagamaan dalam hidupnya. Maka dari itu, penanaman nilai keagamaan dinilai mampu menyajikan suatu pemahaman kepada siswa akan nilai-nilai religious, tidak hanya sekedar penghafalan belaka namun juga perlu untuk memahami aspek afeksi dan psikomotorik (Fathurrohman, 2015: 199).

Berdasarkan penelitian peneliti di SMAN 1 Tembilahan adalah salah satu sekolah yang mempunyai program keahlian berbeda-beda, guru dan peserta didik pun mempunyai latar belakang yang berbeda, baik dari segi agama, budaya, social dan ekonomi. Menurut hasil observasi yang dilakukan peneliti di SMAN 1 Tembilahan, sekolah tersebut memiliki nilai religiusitas yang tinggi. Warga sekolah mayoritas beragama islam juga pengaruh guru Pendidikan agama Islam dalam menciptakan suasana yang islami meskipun SMAN 1 Tembilahan merupakan sekolah umum tidak memungkinkan bila keislaman tertanam pada siswa muslim di SMAN 1 Tembilahan guru dalam menanamkan nilai-nilai keislaman pada siswa melalui beberapa kebiasaan seperti shalat dhuha, shalat berjamaah dan lain-lain. Selain itu para guru yang mengajar di sekolah ini juga mayoritas muslim namun juga ada guru yang non muslim, sekolah ini mempunyai banyak kegiatan keislaman dan juga banyak meraih prestasi-prestasi keislaman yang membuatnya berbeda dengan sekolah-sekolah umum lainnya yang berbasis islam.

SMA N 1 Tembilahan merupakam sekolah negeri umum yang berbeda dengan sekolah yang berada di bawah naungan Kementrian Agama (Kemenag). Tetapi berdasarkan perbedaan tersebut, tidak membuat SMAN 1 Tembilahan kalah saing dengan sekolah-sekolah yang berbasis Islam. 
Dengan membiasakan kegiatan-kegiatan keislaman, walaupun sekolah umum juga bisa diterapkan untuk membentuk kepribadian islami yang lebih mendekatkan diri kepada Allah SWT, sebab kepribadian dapat tumbuh karena adanya kebiasaan.

Berdasarkan grandtour di atas, maka peneliti tertarik untuk melakukan penelitian lebih lanjut tekait penanaman nilail-nilai keislaman di SMAN 1 Tembilahan Kabupaten Indra Giri Hilir dengan judul “Tanggung Jawab Guru Pendidikan Agama Islam Dalam Menanamkan Nilai-Nilai Keislaman pada Siswa SMAN 1 Tembilahan Kabupaten Indra Giri Hilir”.

\section{METODE PENELITIAN}

Penelitian ini menerapkan pendekatan kualitatif sebagai upaya untuk menjawab suatu masalah yang sedang dihadapi karena sifatnya menggunakan penekatan analisis deskriptif (Syaodih, 2011:105). Oleh sebab itu, penelitian ini akan mengilustrasikan kondisi yang sedang terjadi dilihat dari data yang diperoleh dari lapangan. Lalu, data yang diperoleh tersebut dianalisis berupa variable yang satu dengan lainnya. Variable dalam penelitian ini yaitu tentang tanggung jawab guru pendidikan agama islam dalam menanamkan nilai agama islam kepada murid-murid SMAN 1 Tembilahan Kabupaten Indragiri Hilir.

Metode penelitian kualitatif merupakan suatu metode yang dimanfaatkan untuk penelitian obyek yang alamiah dimana peneliti merupakan key informant. Teknik pengumpulan data diambil dengan gabungan (triangulasi), analisis data memiliki sifat induktif, dan hasil penelitian kualitatif lebih bersifat sebagai makna dibanding generalisasi (Sugiyono, 2015:1)

Sasaran dari penelitian ini adalah Tanggung Jawab Guru Pendidikan Agama Islam untuk menanamkan nilai religious agama islam kepada para siswa SMAN 1 Tembilahan Kabupaten Indragiri Hilir. Tempat penelitian adalah di Sekolah SMA N 1 Tembilahan. Jenis data yang digunakan dalam penelitian ini adalah data primer dan data sekunder. Data primer merupakan data yang diperoleh dari sumber pertama di lapangan. Sedangkan data sekunder diperoleh dari gambaran lokasi penelitian, keadaan lingkungan dan sumber pendukung atau referensi yang dijadikan rujukan dalam penelitian (Mukhtar. 2007:58).

Dalam hal ini Tanggung Jawab Guru Pendidikan Agama Islam untuk pembentukan nilai keislaman kepada Siswa SMAN 1 Tembilahan Kabupaten Indragiri Hilir. Teknik pengumpulan data yang digunakan dalam penelitian ini yaitu observasi, wawancara dan dokumentasi (Suharsimi Arikunto, 2010:156). Observasi mengenai Tanggung Jawab Guru Pendidikan Agama Islam Dalam Menanamkan NilaiNilai Keislaman Pada Siswa SMAN 1 Tembilahan Kabupaten Indragiri Hilir. 


\section{HASIL PENELITIAN}

Bentuk-bentuk nilai-nilai keislaman di SMAN 1

Tembilahan kabupaten Indragiri Hilir

Mengenai bentuk-bentuk nilai-nilai keislaman di SMA N 1 Tembilahan. Terdapat tiga nilai yang digunakan untuk menanamkan nilai keislaman siswa dalam pembelajaran, yaitu:

\section{Nilai Iman}

Nilai iman merupakan nilai dasar. Siswa diharapkan dapat memahami makna iman yang sesungguhnya dan penerapannya dalam kehidupan sehari-hari. Adapun nilainilai keimanan yang ditanamkan keapada siswa SMAN 1 Tembilahan adalah:

\section{Imanan kepada Allah SWT}

Dengan cara ini, siswa diajarkan tentang keberadaan Allah SWT sebagai pencipta dan pemilik seluruh alam dan seisinya.

\section{Imanan kepada kitabullah Al-quran}

Iman terhadap kitab Allah artinya dengan sepenuh hati yakin dan percaya bahwa bahwa Allah mengilhamkan kitab-kitab-Nya kepada para Rasul-Nya. Di dalam kitab tersebut, terdapat ajaran-ajaran yang berisikan pedoman agar umat manusia meraih kebahagian di dunia maupun di akhirat.

\section{Imanan kepada Rasul}

Percaya dan yakin dengan sepenuh hati bahwa rasul adalah Utusan Allah merupakan makna dari Iman terhadap Rasul Allah.

\section{Imanan kepada Malaikat-malaikat utusan Allah}

Iman kepada malaikat memiliki makna mengenal nama dan tugas malaikat sebagai utusan Allah SWT. Dalam hasil wawancara dengan siswa, disampaikan bahwa dalam menanamkan makna iman kepada malaikat dilakukan dengan cara mengenalkan nama dan tugasnya menggunakan lagu islami agar lebih mudah dihafalkan.

\section{Imanan kepada qadha dan qadar}

Iman kepada qadha dan qadar dapat diajarkan kepada siswa yang merupakan perintah Allah SWT agar siswa dengan mudah memahaminya dalam kehidupan sehari-hari. Segala yang terjadi ataupun yang akan terjadi telah ditakdirkan oleh Allah SWT. Hal tersebut merupakan ketetapakan dari Allah SWT sebagai pemilik seluruh alam dan isinya. Ketetapan Allah tersebut sudah ada dari Zaman Azali dan disebut Qadha. Sedangkan qadar merupakan perwujudan dari qadha.

Dilihat dari uraian tersebut, peneliti dapat menyimpulkan bahwa bahan ajar yang disajikan oleh guru yaitu tentang rukun iman dalam islam dan cara menerapkannya. Maka, dalam mengajar dapat dilakukan dengan menggunakan media gambar bertemakan rukun iman, rukun Islam, nama-nama malaikat, nama-nama Nabi dan shalat lima waktu. 
Nilai Ibadah

Nilai ibadah yang diterapkan di SMA

N 1 Tembilahan ini adalah dengan kegiatan berdoa sebelum melaksanakan proses belajar dengan membaca beberapa surat pendek. Menjalankan ibadah shalat dhuha jamaah saat pelaksanaan mata pelajaran agama islam pada jam pelajaran pagi. Melaksanakan shalat zhuhur berjamaah. Yasinan Setiap Pagi Jum'at. Program SABAR (SMANSA Berbagi Ramadhan). Memperingati hari besar Islam. Kegiatan Rebana. Kajian Islam, dan Kegiatan MABIT (Malam Bina Iman dan Taqwa).

\section{Nilai Akblak}

Akhlak adalah suatu sikap yang ada pada tiap siswa, apabila siswa tidak ditanamkan Pendidikan akhlak maka kemungkinan siswa tersebut hanya pintar karena memiliki banyak ilmu namun memiliki tingkah laku dan sikap yang kurang baik. Dengan adanya pendidikan akhlak, siswa diharapkan memiliki ilmu dan pemahaman yang seimbang yaitu antara ilmu keterampilan akademik dan juga perilaku yang baik berdasarkan Alquran dan Hadits. Materi pmbelajaran untuk diajarkan kepada siswa untuk Pendidikan nilai akhlak yaitu membuat siswa terbiasa untuk melakukan kegiatan agama seperti melakukan interaksi secara terbuka agar siswa senantiasa untuk berkata jujur. Selain itu juga dapat memberi teguran untuk siswa yang melakukan kesalahan.
Faktor Pendukung Guru Pendidikan Agama Islam dalam Menanamkan Nilai-Nilai KeIslaman pada Siswa SMAN 1 Tembilaban Kabupaten Indra Giri Hilir

Terdapat faktor pendukung dalam mengajarkan nilai-nilai keagamaan di SMAN 1 Tembilahan yaitu: terdapat visi dan misi dari SMAN 1 Tembilahan, dukungan dari pihak sekolah dengan memberikan sarana dan prasarana yang memadai, Faktor Lingkungan juga yang masyarakatnya religius, dukungan dari komite sekolah, dukungan dari kepala sekolah serta danya Mentoring.

Tanggung Jawab Guru Pendidikan Agama Islam dalam Menanamkan Nilai-nilai Keislaman pada Siswa SMA N 1 Tembilahan

Dilihat dari hasil wawancara, dapat di ketahui bahwa guru PAI telah melakukan pembelajaran susuai dengan kurikulum yang ada di sekolah, kemudian guru PAI juga membimbing siswa dalam kegiatan ekstrakurikuler agama yang ada di sekolah. Kepala sekolah pun mengatakan bahwa telah di lakukan monitoring evaluasi kepada guru PAI dan mereka sudah menjalankan tugasnya susuai dengan kurikulum yang ada, dan di tambah dengan kegiatan-kegiatan keagamaan lainnya di luar jam sekolah.

Guru PAI di SMAN 1 Tembilahan tak hanya mengejar saat jadwal pelajaran namun juga memberikan Pendidikan nilai islam pada kegiatan ektrakurikuler yang ada di sekolah. Hal tersebut dikarenakan menurut 
para guru, pembelajaran teori saja tidak cukup.

Hasil yang dicapai dari tanggung jawab guru dalam menanamkan nilai-nilai keislaman di SMAN 1 Tembilaban kabupaten Indragiri Hilir

Dengan adanya agama Islam yang disampaikan oleh Nabi Muhammad SAW diyakini dapat menjamin terwujudnya kehidupan manusia yang sejahtera lahir dan batin. Di dalam Al-quran dan hadist, telah tertulis ajaran yang ideal sebagai petunjuk untuk umat manusia. Islam mengajarkan kehidupan yang dinamis dan progresif, menghargai akal pikiran melalui pengembangan ilmu pengetahuan dan teknologi, bersikap seimbang dalam memenuhi kebutuhan material dan spiritual, senantiasa mengembangkan kepedulian sosial, menghargai waktu, bersikap terbuka, demokratis, berorientasi pada kualitas, egaliter, kemitraan, anti-feodalistik, mencintai kebersihan, mengutamakan persaudaraan, berakhlak mulia dan bersikap positif lainnya.

Keislaman di SMA Negeri 1 Tembilahan yang peneliti temukan, bahwa sekolah SMA Negeri 1 Tembilahan ini adalah sekolah umum namun bernuansa islami, hal ini dapat dilihat dari siswi yang muslim semua mengenakan jilbab, serta guru-guru muslimah semua juga mengenakan jilbab. Dan para siswa yang juga selalu bersalaman ketika bertemu dengan guru baik di luar kelas maupun di dalam kelas, dan setiap guru masuk kelas untuk memberikan materi siswa bersalam dan kemudian selesai materi ketika guru hendak keluar kelas siswa-siswi juga selalu bersalaman kepada guru-gurunya. Siswa SMA Negeri 1 Tembilahan ini juga melakukan shalat dhuha bersama, dan shalat zhuhur berjama'ah di mushalla sekolah di dampingi langsung oleh guru PAI.

Berdasarakan hasil wawancara di atas, disimpulkan bahwa SMAN 1 Tembilahan mempunyai nilai keislaman cukup baik dikarenakan mendapat dukungan dari aspek lingkungan. Dalam faktor yang lebih intern tolak ukur SMA N 1 Tembilahan menjadi sekolah dengan keislaman yang baik yaitu bentuk yang dilakukan guru PAI dalam menanamkan nilai-nilai keislaman kepada murid sehingga dapat terciptanya siswa yang mampu beradaptasi sesuai ajaran Islam baik di dalam sekolah, maupun di lingkungan sekolah.

Disamping itu observasi mengenai hasil kegiatan-kegiatan keislaman atau prestasi yang diperoleh oleh sekolah SMA N 1 Tembilahan, diantaranya ialah: Juara 1 lomba sholawat Bariyah tahun 2015, Juara 3 lomba sholawat tarhim (sebelum adzan Maghrib), Juara 3 lomba adzan tingkat SMA/Madrasah, Juara 1 pawai ta'aruf $\mathrm{dlm}$ rangka tahun baru islam, Harapan 1 lomba da'i/da'iah muda tingkat kabupaten, Juara 1 pawai idul adha, Juara 1 Sholawat Mariah, Juara 2 syair ibarat Tuan guru syekh Abdurrahman Shiddiq, Juara 3 Lomba Habsy tingkat SMA dan Ponpes se kab inhil, Juara 2 
maulid Habsy tingkat SMA/Sederajat, dan MTQ kab Inhil harapan 3.

Dari hasil observasi, wawancara serta dokumentasi bahwa sekolah SMA Negeri 1 Tembilahan adalah sekolah umum yang banyak mempunyai prestasi, tidak hanya prestasi umum tetapi prestasi keislaman juga ada, dari sini dapat kita lihat bahwa sekolah ini adalah sekolah yang mempunyai kelebihan yang luar biasa, karena prestasi keagamaan yang diraih tidak kalah dengan sekolahsekolah agama yang ada.

\section{KESIMPULAN}

Adapun bentuk-bentuk niali keislaman yang diterapkan di SMA N 1 Tembilahan ialah, nilai iman yang mencakup dari rukun iman. Kemudain nilai ibadah yaitu Kegiatan berdoa sebelum memulai pembelajaran dengan membaca surat-surat pendek, Melaksanakan shalat dhuha berjamaah ketika pelajaran agama di waktu pagi, Melaksanakan shalat zhuhur berjamaah, Yasinan Setiap Pagi Jum'at, Program SABAR (SMANSA Berbagi Ramadhan), Memperingati hari besar Islam, Kegiatan Rebana, Kajian Islam, Kegiatan MABIT (Malam Bina Iman dan Taqwa). Serta nilai akhlak.

Faktor pendukung guru Pendidikan Agama Islam dalam menanamkan nilai-nilai keislaman pada siswa di SMA $\quad \mathrm{N} 1$ Tembilahan, dalam faktor pendukung berasal dari lingkungan yaitu dengan adanya masyarakat di lingkungan sekolah yang sangat religius, selain itu mendapat dukungan penuh dari kepala sekolah dan komite sekolah, Visi Misi sekolah yang sesuai, dan Mentoring.

Tanggung jawab guru PAI dalam menanamkan nilai-nilai keislaman pada siswa di SMA N 1 Tembilahan, bahwa guru PAI telah menjalankan tugas dan kewajibannya serta tanggung jawabnya sebagai guru PAI untuk menanamkan nilai-nilai keislman pada siswa, dan semua susuai dengan kurikulum yang ada di sekolah, kemudian guru PAI juga membimbing siswa dalam kegiatan ekstrakurikuler agama yang ada di sekolah. Guru pendidikan Agama Islam dalam menanamkan nilai-nilai keislaman pada siswa di SMA N 1 Tembilahan dengan pembiasaan.

Hasil kegiatan-kegiatan keislaman di SMA N 1 Tembilahan, terlihat bahwa siswisiswi SMA N 1 Tembilahan semua mengenakan jilbab bagi yang muslim, aklah serta tingkah laku siswa-siswinya juga baik, serta banyak prestasi-prestasi keislaman yang di raih oleh SMA N 1 Tembilahan diantaranya Juara 1 lomba sholawat Bariyah tahun 2015, Juara 3 lomba sholawat tarhim (sebelum adzan Maghrib), Juara 3 lomba adzan tingkat SMA/Madrasah, Juara 1 pawai ta'aruf dlm rangka tahun baru islam, Harapan 1 lomba da'i/da'iah muda tingkat kabupaten, Juara 1 pawai idul adha, Juara 1 Sholawat Mariah, Juara 2 syair ibarat Tuan guru syekh Abdurrahman Shiddiq, Juara 3 Lomba Habsy tingkat SMA dan Ponpes se kab inhil, Juara 2 maulid Habsy tingkat SMA/Sederajat, dan MTQ kab Inhil harapan 3. 


\section{DAFTAR PUSTAKA}

Agama, D. (2002). Al-Qur'an dan Terjemahannya. Jakarta: Departemen Agama RI.

Aly, E. N. (1999). Ilmu Pendidikan Islam. Jakarta: Logos Wacana Ilmu.

Amri, S. (2013). Peningkatan Mutu Pendidikan Sekolah Dasar dan Menengah dalam Teori Konsep dan Analisis. Jakarta: Pustaka Raya.

Arcaro, Z. S. (2015). Pendidikan Berbasis Mutu; Prinsip -Prinsip dan Tata Langkah Penerapan. Yogyakarta: Pustaka Pelajar.

Arief, A. (2002). Pengantar Ilmu dan Metodologi Pendidikan Islam . Jakarta: Ciputat Press.

Arikunto, S. (2008). Penelitian Tindakan Kelas. Jakarta: Bumi Aksara.

Arikunto, S. (2010). Prosedur Penelitian; Satu pendekatan Praktik. Jakarta: Rineka cipta.

Barnawi, \& Arifin, M. (2012). Strategi \& Kebijakan Pembelajaran Pendidikan Karakter. Yogyakarta: AR RUZZ MEDIA.

Djumransyah, \& Amrullah, A. M. (2007). Pendidikan Islam. Malang: UINMalang Pers.

Dwi, R. (2009). Kamus Ensiklopedi Umum Bahasa Indonesia. Bandung: PT Prakarya.

Fakhruddin, A. U. (2011). Menjadi guru favorit. Yogyakarta: DIVA Press.
Fathurrohman, M. (2015). Budaya Religius dalam meningkatkan Mutu Pendidikan. Yogyakarta: Kalimedia.

Gunawan, H. (2012). Pendidikan karakter Konsep dan Implementasi. Bandung: Alfabeta.

Iskandar. (2009). Metodologi Penelitian Kualitatif. Jakarta: Gp Press.

Jalaluddin. (2016). Psikologi Agama. Jakarta: Raja Grafindo Persada.

Karwati, E., \& Priansa, D. J. (2013). Kinerja dan Profesionalisme Kepala Sekolab: Membangun Sekolah yang Bermutu. Bandung: Alfabeta.

Majid, A., \& Andayani, D. (2004). Pendidikan Agama Islam Berbasis Kompetensi. Bandung: Remaja Rosdakarya.

Majid, A., \& Andayani, D. (2011). Pendidikan Karakter Persepektif Islam. Bandung: PT. Remaja Rosdakarya.

Moleong, L. J. (2010). Metodologi Penelitian Kualitatif. Bandung: Rosda Karya.

Mufron, A. (2013). Ilmu pendidikan Islam. Yogyakarta: Aura Pustaka .

Mukhtar. (2007). Bimbingan Skripsi, Tesis, Artikel Ilmiah. Jambi: Sulthan Thaha Press.

Mulyana, R. (2004). Mengartikulasikan Pendidikan Nilai. Bandung: Alfabeta.

Mulyasa. (2011). Menjadi guru Profesional. Bandung: PT. Remaja Rosdakarya.

Sahlan, A. (2010). Mewujudkan Budaya Religius di Sekolab: Upaya mengembangkan PAI dari Teori ke Aksi. Malang: UINMALIKI PRESS. 
Salman. (2012). Tuntutan Menjadi guru Favorit. Yogyakarta: flashbooks.

Shaleh, A. R. (2005). Pendidikan Agama \& Pembangunan Watak Bangsa. Jakarta: Rajagrafindo Persada.

Sugiyono. (2015). Memahami Penelitian Kualitatif. Bandung: Alfabeta.

Sukmadinata, N. S. (2011). Metodologi Penelitian Kualitatif. Bandung: Remaja Rosda Karya.

Thoha, C. (2000). Kapita Selekta Pendidikan Islam. Yogyakarta: Pustaka Pelajar.
Tilaar, H. A. (2002). Membenabi Pendiidikan Nasional. Jakarta: PT. Rineka Cipta.

Usman, H. (2006). Manajemen: Teori, Praktik dan Riset Pendidikan. Jakarta: Bumi Aksara.

Walgito, B. (2002). Pengantar Psikologi Umum. Yogyakarta: ANDI.

Zahroh, A. (2015). Membangun Kualitas Pembelajaran Melalui Dimensi Profesionalisme Guru. Bandung: Yrama Widya. 